\title{
PDGFRa/ $\beta$ and VEGFR2 polymorphisms in colorectal cancer: incidence and implications in clinical outcome
}

\author{
Purificacion Estevez-Garcia ${ }^{1,2}$, Angel Castaño ${ }^{3}$, Ana C Martin ${ }^{4}$, Fernando Lopez-Rios ${ }^{5}$, Joaquin Iglesias ${ }^{4}$, \\ Sandra Muñoz-Galván ${ }^{1}$, Iker Lopez-Calderero ${ }^{1,2}$, Sonia Molina-Pinelo ${ }^{1}$, Maria D Pastor ${ }^{1}$, Amancio Carnero ${ }^{1}$, \\ Luis Paz-Ares ${ }^{1,2}$ and Rocio Garcia-Carbonero ${ }^{1,2^{*}}$
}

\begin{abstract}
Background: Angiogenesis plays an essential role in tumor growth and metastasis, and is a major target in cancer therapy. VEGFR and PDGFR are key players involved in this process. The purpose of this study was to assess the incidence of genetic variants in these receptors and its potential clinical implications in colorectal cancer (CRC).

Methods: VEGFR2, PDGFRa and PDGFR $\beta$ mutations were evaluated by sequencing their tyrosine kinase domains in 8 CRC cell lines and in 92 samples of patients with CRC. Correlations with clinicopathological features and survival were analyzed.

Results: Four SNPs were identified, three in PDGFRa [exon 12 (A12): c.1701A>G; exon 13 (A13): c.1809G>A; and exon 17 (A17): C.2439+58C>A] and one in PDGFRB [exon 19 (B19): c.2601A>G]. SNP B19, identified in 58\% of tumor samples and in 4 cell lines (LS174T, LS180, SW48, COLO205), was associated with higher PDGFR and pPDGFR protein levels. Consistent with this observation, 5 -year survival was greater for patients with PDGFR B19 wild type tumors (AA) than for those harboring the G-allele genotype (GA or GG) (51\% vs 17\%; $p=0.073)$. Multivariate analysis confirmed SNP B19 $(p=0.029)$ was a significant prognostic factor for survival, independent of age $(p=0.060)$ or TNM stage $(p<0.001)$.
\end{abstract}

Conclusions: PDGFRß exon 19 c.2601A>G SNP is commonly encountered in CRC patients and is associated with increased pathway activation and poorer survival. Implications regarding its potential influence in response to PDGFR-targeted agents remain to be elucidated.

Keywords: VEGFR, PDGFR, SNP, Colorectal cancer, Angiogenesis, Prognosis

\section{Background}

Colorectal cancer (CRC) is the third most common tumour in the world, with over 1.2 million new cases diagnosed every year, and is responsible for about $8 \%$ of cancer related deaths [1]. Approximately one third of patients present metastatic disease at diagnosis, and about $40 \%$ of those with early-stage tumors will eventually relapse at some point over the course of the disease $[2,3]$. Although prognosis has greatly improved over the

\footnotetext{
* Correspondence: rgcarbonero@hotmail.com

${ }^{1}$ Instituto de Biomedicina de Sevilla (IBIS) (HUVR, CSIC, Universidad de

Sevilla), Sevilla, Spain

${ }^{2}$ Medical Oncology Department, Hospital Universitario Virgen del Rocio,

Sevilla, Spain

Full list of author information is available at the end of the article
}

past decades due to significant surgical and medical advances, once the tumor has progressed beyond surgical resectability, the disease is essentially incurable and median survival ranges from 14 to 24 months with best available systemic therapy [4]. Development of new more effective agents is thus actively pursued.

Angiogenesis has become a major target in colorectal cancer therapy. Bevacizumab, a humanized monoclonal antibody against the vascular endothelial growth factor A (VEGF-A), was the first antiangiogenic agent to demonstrate efficacy in CRC. In the pivotal study by Hurwitz et al., the addition of this agent to irinotecan-based combination cytotoxic therapy significantly improved survival compared to irinotecan-based chemotherapy alone
C Biomed Central

(c) 2012 Estevez-Garcia et al.; licensee BioMed Central Ltd. This is an Open Access article distributed under the terms of the Creative Commons Attribution License (http://creativecommons.org/licenses/by/2.0), which permits unrestricted use, distribution, and reproduction in any medium, provided the original work is properly cited. 
in patients with advanced CRC [5]. Subsequently, bevacizumab has been tested in combination with other chemotherapy regimens with more modest results [3,4]. More recently, a benefit in survival has been also reported in patients with advanced CRC with two new promising antiangiogenic drugs: aflibercept (a VEGF trap) in combination with FOLFIRI (folinic acid, 5-fluoruracil and irinotecan) following progression to oxaliplatin-based therapy [6], and regorafenib (a novel tyrosine kinase inhibitor targeting VEGFR, PDGFR, FGFR, RET, KIT and TIE2) as single-agent therapy in patients who had progressed to all standard therapies [7]. These results clearly illustrate angiogenesis inhibition is to play a major role in the management of this disease.

Angiogenesis is a highly controlled process under physiological conditions, such as embryonal development, postnatal growth and wound healing, but is also a critical driver of tumor growth and progression [8]. It is tightly regulated by a complex equilibrium among different pro- and antiangiogenic factors secreted both by tumor cells and by cells of the tumor microenvironment (pericytes, endothelial, mesenchymal or immune cells). VEGF and their receptors represent one of the best validated pathways involved in angiogenesis [9,10]. VEGF stimulates both proliferation and migration of endothelial cells, enhances microvascular permeability, and is essential for revascularization during tumor formation. It is commonly over-expressed in human tumors, and this is often associated with increased vascular density and more aggressive clinical behavior. VEGF-A and its main receptor, VEGFR2/KDR, are key members of this family and common targets of antiangiogenic agents $[11,12]$.

Platelet-derived growth factor (PDGF) and their receptors (PDGFR- $\alpha$, PDGFR- $\beta$ and PDGFR- $\alpha \beta$ ) play also a critical role in angiogenesis regulation by exerting important control functions in mesenchymal cells during development [13]. PDGF is expressed by endothelial cells and acts in a paracrine manner by recruiting PDGFR-expressing cells, such as pericytes and smooth muscle cells, to the developing vessels, thus improving pericyte coverage and vessel function. PDGF signaling promotes cell migration, survival and proliferation and indirectly regulates angiogenesis by inducing VEGF transcription and secretion $[10,13,14]$. Mutations involving up-regulation of PDGF and/or PDGFR, as well as PDGFR-dependent growth stimulation, have been documented in a number of solid tumors and hematological malignancies, suggesting a likely role of this pathway in carcinogenesis $[10,15]$. Moreover, agents antagonizing PDGFR-mediated signaling have also demonstrated antineoplastic activity in preclinical models and in clinical trials, including some conducted in patients with CRC (i.e. regorafenib) [7]. Nevertheless, several other drugs also targeting these pathways (i.e. sunitinib, sorafenib) $[16,17]$ have failed to prove a significant positive impact on the outcome of patients with CRC. The biological grounds for these discordant results are not well understood.

Therefore, and in spite of their undeniable success, only a small proportion of patients do actually benefit from antiangiogenic agents, and reliable tools to prospectively identify which patients are more likely to benefit are scarce. In this scenario, efforts to unravel the intricate molecular pathways governing tumor angiogenesis are certainly needed for progress to be made. In the present study, we sought to evaluate the incidence of genetic polymorphisms of some of the key players of angiogenesis, such as VEGFR-2, PDGFR- $\alpha$ and PDGFR$\beta$, and their potential influence in CRC biology. With this purpose we sequenced the tyrosine kinase domains of these receptors in 8 CRC cell lines (T84, LOVO, LS174T, HT29, LS180, SW48, SW480, COLO205) and in 92 tumor samples of patients with colorectal adenocarcinoma. Correlations of encountered genetic variables with protein expression in cell lines, as well as with clinicopathological features and survival of these patients were also analyzed to assess their potential biological and clinical implications.

\section{Methods}

\section{Laboratory procedures}

CRC cell lines

Eight human CRC cell lines (T84, LOVO, LS174T, HT 29, LS180, SW48, SW480 and COLO205) were selected and purchased from the European Collection of Cell Cultures (ECACC). They were representative of patients with different gender, age and tumor stage.

\section{Cell culture}

Each cell line was grown in conditions of temperature, humidity, $\mathrm{O}_{2}$ and $\mathrm{CO}_{2}$ levels, culture medium and supplements according to providers' instructions. Once they reached confluence in monolayer DNA extraction was performed. The total DNA yield was determined using a Nanodrop ND-1000 spectrophotometer (Nanodrop Tech, DE, USA).

\section{DNA isolation from human tumor samples and culture cells}

Formalin-fixed paraffin-embedded tissues from the 92 selected CRC patients were provided by the Pathology Departments of the corresponding institutions. Samples were mainly obtained from the primary tumor $(96 \%)$, either by surgical (87\%) or endoscopic procedures. Three tissue sections of each tumor were first deparaffinized and rehydrated by serial passes in DLimoneno (Histo-Clear ${ }^{\circledR}$, National Diagnostic, Atlanta, GA, USA) and ethanol (100\%). Then, DNA isolation from both human tumor tissue samples and culture cells 
was performed with the REAL pure genomic DNA extraction kit (Durviz, Valencia, Spain) according to the manufacturer's instructions and then purified using ion exchange columns (QIAGEN Miniprep kit Cat. No. 27106). The total DNA yield was determined using a Nanodrop ND-1000 spectrophotometer (Nanodrop Tech, DE, USA).

\section{Genotyping}

Public databases including National Center for Biotechnology Information (NCBI) (http://www.ncbi.nlm.nih. gov), University of California Santa Cruz (UCSC) Genome Bioinformatics (http://genome.ucsc.edu) and Ensembl Genome Browser (http://www.ensembl.org/index.html) were reviewed to obtain the haplotypes of the three genes of interest and their reported genetic variants. The exomic regions corresponding to the tyrosine kinase domains, which were the regions with the highest probability of mutations, were then identified for each gene: exons 17 to 26 for VEGFR2, and exons 12 to 21 for PDGFR $\alpha$ and PDGFR $\beta$. Specific primers were designed to amplify these exons using expert software in order to minimize non-specific or erroneous amplifications and improve outcomes. Primers used in this study are described in Additional file 1: Table S1. Amplification of the tyrosine kinase domains in both CRC cell lines and tissue samples was performed by a polymerase chain reaction (PCR) method. Fifty nanograms of the genomic purified DNA were amplified in a PCR reaction containing 1.5 units of DNA polymerase EuroTAQ (Genycell Biotech Spain SL; Santa Fe, Granada, Spain), 1xEuroTaq buffer, $2.5 \mathrm{mM}$ $\mathrm{Mg}^{2+}, 0.4 \mu \mathrm{M}$ forward and reverse primers, $80 \mu \mathrm{M}$ dNTPs (20 $\mu \mathrm{M}$ each one), 1\% DMSO and $1 \mathrm{M}$ betaine in a volume of $50 \mu \mathrm{l}$. The PCR cycling conditions were as follows: initial denaturation at $94^{\circ} \mathrm{C}$ for 5 minutes, 5 cycles at $94^{\circ} \mathrm{C}$ for 1 minute, and annealing that began at $67^{\circ} \mathrm{C}$ for 45 seconds; this temperature was decreased $2^{\circ} \mathrm{C}$ each cycle to $59^{\circ} \mathrm{C}(67,65,63,61,59)$ and then 45 seconds at $72^{\circ} \mathrm{C}$. This was followed by 35 cycles at $95^{\circ} \mathrm{C} 1$ minute, $55^{\circ} \mathrm{C}$ for 45 seconds and $72^{\circ} \mathrm{C}$ for 45 seconds. The last step was a final extension cycle at $72^{\circ} \mathrm{C}$ for 10 minutes.

\section{DNA sequencing}

PCR products were first purified using the microClean kit (Microzone Ltd.; Haywards Heath, UK) or ExoSAP$\mathrm{IT}^{\circledR}$ for PCR Product Clean-Up USB (Affimetrix Inc; Santa Clara, CA, USA) for individual reactions or PERFORMA ${ }^{\circledR}$ DTV V396-Well Short Plates (Genycell Biotech Spain SL; Santa Fe, Granada, Spain) for 96 plate reactions. Direct bidirectional sequencing of the PCR products was done using BigDye ${ }^{\circledR}$ Terminator Cycle v3.1 Sequencing Kit (Applied Biosystems; Carlsbad, CA, USA) and ABI 3110 Genetic Analyser (Applied
Biosystems) according to the manufacturer's instructions. All fragments were double-strand sequenced a number of times, and genetic variations found were checked twice. Sequencing analysis was performed using Chromas Lite, Clustal W and DiAlign software.

\section{Analysis of protein expression}

Cells were washed twice in $1 \times$ PBS, pelleted for $30 \mathrm{sec}-$ onds at $14000 \times \mathrm{g}$ and lysed in lysis buffer (Tris- $\mathrm{HCl} \mathrm{pH}$ $7.550 \mathrm{mM}$, NP40 1\%, glycerol 10\%, NaCl 150mM, complete protease inhibitor cocktail, $2 \mathrm{mM}$; Roche). After centrifugation, supernatant protein extracts were aliquoted and stored at $-80^{\circ} \mathrm{C}$ until use. The amount of protein was determined by Bradford assay using BSA (bovine serum albumin) as a standard. The appropriate protein quantity was dissolved in Laemli buffer (Tris$\mathrm{HCl}$ pH $6.862 .5 \mathrm{mM}$, glycerol 10\%, SDS 1\%, 2-mercapto ethanol 5\%, bromphenol blue $0.0025 \%$ ) and the proteins were separated in SDS-PAGE gels (12\%) before they were blotted onto Nitrocellulose Transfer membrane (Whatman - Protrans). Primary antibodies employed were: p-PDGFR- $\beta$ (Tyr1021)-R 1:400 (Santa Cruz\#sc12909-R), PDGFR- $\beta$ 1:500 (Santa Cruz\#sc-339), tubulin 1:10000 (Sigma - T6557). The secondary antibodies used were goat anti-rabbit Alexa Fluor 680 1:5000 (Invitrogen - A21057) and donkey anti-mouse IRDye 800CW 1:5000 (Rockland Inc. - 605-731-002).

\section{CRC study population, tumor samples and data collection}

Patients that met the following inclusion criteria were selected for the present study: (1) histologically confirmed diagnosis of primary CRC; (2) adequate clinical data recorded in medical charts; (3) adequate tissue specimen available for additional molecular assays (a proportion of tumor cells $>50 \%$ was required). Cases were reviewed according to a previously designed protocol which included the following clinical data: age, sex, date of diagnosis, baseline carcinoembryonic antigen (CEA) plasma levels, primary tumor location, TNM stage [18], histological type, tumor differentiation, surgical treatment (type and outcome of surgery), chemotherapy (adjuvant or for advanced disease, regimen used), radiotherapy (neoadjuvant, adjuvant or palliative), date of last visit or death and cause of death. The study protocol was approved by the institutional review boards of participating centers.

Main characteristics of the 92 included patients are summarized in Table 1 and are representative of a standard CRC population. The median age was 68 years, $63 \%$ were male and $40 \%$ presented advanced disease at diagnosis. The great majority had conventional adenocarcinomas (86\%) and only $13 \%$ were poorly differentiated tumors. Cancer specific therapy is outlined in Additional file 1: Table S2. Patients with early stage disease (I-III) 
Table 1 Population and tumor samples characteristics

\begin{tabular}{|c|c|}
\hline & $\mathrm{N}(\%)$ \\
\hline \multicolumn{2}{|l|}{ Age (years) } \\
\hline - Median (range) & $68(45-87)$ \\
\hline \multicolumn{2}{|l|}{ Gender } \\
\hline - Female & $34(37.0 \%)$ \\
\hline - Male & $58(63.0 \%)$ \\
\hline \multicolumn{2}{|l|}{ Primary tumor location } \\
\hline - Right colon & $27(29.3 \%)$ \\
\hline - Transverse colon & $5(5.4 \%)$ \\
\hline - Left colon & $9(9.8 \%)$ \\
\hline - Sigmoid colon & $18(19.6 \%)$ \\
\hline - Recto sigmoid colon & $14(15.2 \%)$ \\
\hline - Rectum & $19(20.7 \%)$ \\
\hline \multicolumn{2}{|l|}{ Histology } \\
\hline - Conventional adenocarcinoma & $79(85.9 \%)$ \\
\hline - Mucinous or colloid adenocarcinoma & $12(13.0 \%)$ \\
\hline - Signet ring cell adenocarcinoma & $1(1.1 \%)$ \\
\hline \multicolumn{2}{|l|}{ Tumor differentiation } \\
\hline - Well differentiated & $22(23.9 \%)$ \\
\hline - Moderately differentiated & $46(50.0 \%)$ \\
\hline - Poorly differentiated & $12(13.0 \%)$ \\
\hline \multicolumn{2}{|l|}{ TNM stage } \\
\hline$\cdot \bullet$ & $8(8.7 \%)$ \\
\hline$\cdot \|$ & $22(23.9 \%)$ \\
\hline$\cdot \bullet \| \mid$ & $24(26.1 \%)$ \\
\hline$\cdot \operatorname{lV}$ & $37(40.2 \%)$ \\
\hline - Unknown & $1(1.1 \%)$ \\
\hline \multicolumn{2}{|l|}{ Baseline CEA (ng/mL) } \\
\hline - High & $33(35.9 \%)$ \\
\hline - Normal & $59(64.1 \%)$ \\
\hline - Median (range) & $3(0-13.318)$ \\
\hline
\end{tabular}

TNM: Tumor, Node and Metastases; CEA: carcinoembryonic antigen.

underwent primary tumor surgery with curative intent. Adjuvant fluoropyrimidine-based chemotherapy with or without oxaliplatin was indicated in patients with high risk stage II or stage III CRC following surgical resection. Neoadjuvant or adjuvant radiotherapy was added in stage II-III patients with rectum primaries. Patients with advanced stage IV disease were managed primarily with systemic chemotherapy that included oxaliplatin- (44\%) or irinotecan-based (13\%) combination regimens or fluoropyrimidines alone (3\%). With a median follow-up of 31 months (range: 8 to 99 months), 59 patients (64\%) had died due to disease progression or to complications of cancer therapy.

\section{Statistical analysis}

A minimum sample size of 80 patients was planned to be screened in case no mutations were to be encountered, as in such a case the probability of finding mutations in the general population was estimated to be very low $(\leq 4.4 \%$; $\alpha=0.05, \beta=0.80$ ) and therefore non-clinically relevant. Considering an expected drop-out rate of about $10 \%$ (technical issues or others), 92 patients were finally selected for study entry. Descriptive statistics were used to characterize the most relevant clinical parameters. The association of categorical clinical or pathological features and mutation type was explored by the chi-squared test or Fisher's exact test when appropriate. Overall survival (OS) was calculated from the time of histological diagnosis to the date of death (deaths due to surgical complications were censored). The Kaplan-Meier product limit method [19] was used to estimate OS, and differences observed among patient subgroups were assessed by the $\log$ rank test [20]. Multivariate analysis using the Cox proportional hazards model [21] was performed to assess the association between mutations and clinical outcome while adjusting for other potential confounding factors such as age, tumor stage, primary tumor location, CEA levels and tumor differentiation. $\mathrm{P}<0.05$ was considered significant. All analyses were performed using the Statistical Package for the Social Sciences software (SPSS 16.0 for Windows; SPSS Inc, Chicago, IL).

\section{Results}

\section{Characterization of VEGFR2, PDGFRa and PDGFR $\beta$ genetic variants}

Three genetic variations were identified in PDGFR $\alpha$ (exons 12, 13 and 17) and one in PDGFR $\beta$ (exon 19) with respect to the registered wild type (WT) reference sequence (NM006206 and NM002609, respectively), whereas no VEGFR2 mutations were detected. Those encountered in exons A12, A13 and B19 were silent mutations showing nucleotide substitution in the third base of the codon without modifying the codified aminoacide, while the one detected in A17 was an intronic insertion. All of them corresponded to single nucleotide polymorphisms (SNP) previously described in public databases with reference SNP IDs rs1873778, rs10028020, rs246395 and rs2412559, respectively (Additional file 1: Table S3).

\section{SNPs identified in CRC cell lines}

Both SNP A12 and SNP A17 were found in homozygosis in all CRC cell lines. PDGFR-A13 SNP was present in heterozygosis in two cell lines (LS174T and LS180), and PDGFR-B19 presented a SNP in heterozygosis in four of them (LS174T, LS180, SW48 and SW480).

\section{SNPs identified in CRC patient tumor samples}

PDGFR-A12 and PDGFR-A17 analysis was feasible in all tumor samples, and all of them showed the SNPs variants in homozygosis. PDGFR-A13 was successfully 
analyzed in 73 cases (79\%), being the SNP A13 detected in heterozygosis in $18 \%$ of analyzed samples (13 patients). PDGFR-B19 complete analysis was achieved in 78 patients (85\%), and the SNP B19 was found in $58 \%$ of evaluable samples (45 patients), both in homo- and heterozygosis (7 and 38 patients, respectively). Figure 1 illustrates DNA sequencing of PDGFR $\alpha$ exon 12 and PDGFR $\beta$ exon 19, showing SNPs identified in our population.

\section{Correlation of PDGFRa and PDGFR $\beta$ genetic variants and clinicopathological features}

Distribution of SNPs A13 and B19 according to gender, age, baseline CEA levels, primary tumor location, histological type, TNM stage at diagnosis and tumor differentiation is described in Table 2. The only observed correlations that were of borderline statistical significance were those found between SNP B19 and primary tumor location, and SNP A13 and tumor differentiation. Indeed, the PDGFR B19 SNP was more commonly encountered among patients with colon primaries than in those with primary tumors located in the rectum (63.9\% vs 35.3\%; $\mathrm{p}=0.051)$. On the other hand, PDGFR SNP A13 was never detected in well differentiated tumors, whereas it was identified in $23 \%$ of moderately or poorly differentiated ones $(\mathrm{p}=0.053)$.

\section{PDGFRa and PDGFR $\beta$ genetic variants and colon}

\section{cancer survival}

Overall survival of patients according to PDGFR-A13 and -B19 SNPs identified is depicted in Table 3. No significant impact in overall survival was observed for
SNP A13. On the contrary, 5-year survival of patients PDGFR-B19 WT was substantially greater than that observed in those harboring the SNP (51\% vs 17\%; $\mathrm{p}=0.073$ ) (Figure 2). Multivariate analyses showed the presence of the B19 SNP variant was a significant independent predictor of survival (HR 2.89, $\mathrm{p}=0.029$ ). Other variable that retained independent prognostic value in the Cox regression model was TNM stage $(\mathrm{p}<0.001)$, and age was of borderline significance $(\mathrm{p}=0.060)$ (Additional file 1: Table S4).

\section{Effect of B19 SNP in PDGF receptor levels}

To explore the potential biological relevance of the identified PDGFR-B19 SNP, we assessed PDGFR $\beta$ protein levels in each cell line and correlated them with whether or not they harbored the SNP of interest. Of note, the cell lines that contained the B19 SNP in heterozygosis (LS174T, LS180, SW48 and Colo205) showed higher levels of PDGFR $\beta$ protein than those harboring only the wild type allele (Figure 3). In addition, these higher levels of receptor were associated with higher levels of Tyr1021-phosphorylated receptor (Figure 3), indicating its constitutive activation and increased signaling of the pathway.

\section{Discussion}

The present study evaluated the incidence of VEGFR2, PDGFR $\alpha$ and PDGFR $\beta$ TK domain genetic variants in different CRC cell lines (T84, LOVO, LS174T, HT29, LS180, SW48, SW480, COLO205) and in tumor samples of 92 patients diagnosed of colorectal adenocarcinoma.

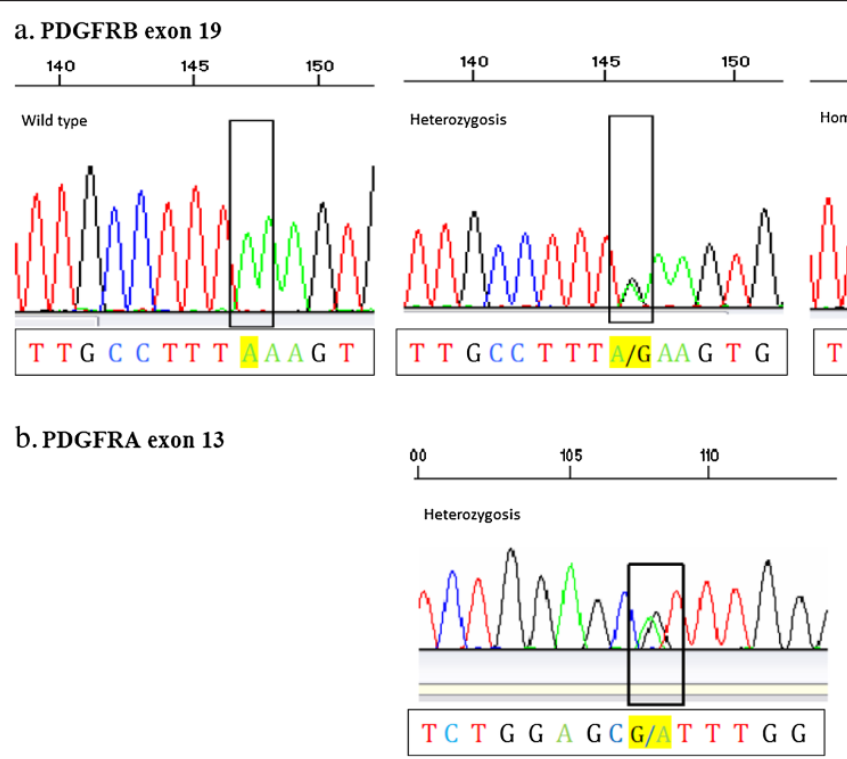

Figure 1 Electropherogram of a PDGFR sequence. 1a: Three examples of paraffin-embedded tumour tissue DNA sequence analysis of PDGFRß exon wild type (Adenine), and SNP B19 in heterozygosis and homozygosis (A to G transition), respectively. 1b: DNA sequence of a paraffin-embedded tumour tissue sample presenting PDGFRa exon 13 SNP in heterozygosis (G to A transition). 
Table 2 Correlation of PDGFR A13 and B19 mutational status and clinical-pathological features

\begin{tabular}{|c|c|c|c|c|c|c|}
\hline \multirow[t]{2}{*}{ Clinical features } & \multicolumn{3}{|c|}{ PDGFRa exon 13} & \multicolumn{3}{|c|}{ PDGFR $\beta$ exon 19} \\
\hline & WT N (\%) & SNP N (\%) & $\mathrm{p}$ & WT N (\%) & SNP N (\%) & $\mathrm{p}$ \\
\hline Gender & & & 0.754 & & & 0.346 \\
\hline - Female & $24(85.7)$ & $4(14.3)$ & & $10(34.5)$ & $19(65.5)$ & \\
\hline - Male & $36(80.0)$ & $9(20.0)$ & & $23(46.9)$ & $26(53.1)$ & \\
\hline Age & & & 0.127 & & & 0.653 \\
\hline - $\leq$ 68-years old (median) & $34(89.5)$ & $4(10.5)$ & & $18(45.0)$ & $22(55.0)$ & \\
\hline - > 68-years old (median) & $26(74.3)$ & $9(25.7)$ & & $15(39.5)$ & $23(60.5)$ & \\
\hline CEA (carcinoembryonic antigen) & & & 1.000 & & & 0.813 \\
\hline - Within normal range & $39(83.0)$ & $8(17.0)$ & & $21(41.2)$ & $30(58.8)$ & \\
\hline • $\geq$ ULN (5 ng/ml) & $21(80.8)$ & $5(19.2)$ & & $12(44.4)$ & 15 (55.6) & \\
\hline Primary tumour location & & & 1.000 & & & 0.051 \\
\hline - Colon & $47(82.5)$ & $10(17.5)$ & & $22(36.1)$ & $39(63.9)$ & \\
\hline Rectum & $13(81.3)$ & $3(18.8)$ & & $11(64.7)$ & $6(35.3)$ & \\
\hline Tumour histology & & & 0.401 & & & 0.221 \\
\hline - Conventional adenocarcinoma & $52(83.9)$ & $10(16.1)$ & & $30(45.5)$ & $36(54.5)$ & \\
\hline - Mucinous or colloid adenocarcinoma & $8(72.7)$ & $3(27.3)$ & & $3(25.0)$ & $9(75.0)$ & \\
\hline TNM stage & & & 0.196 & & & 0.170 \\
\hline$\cdot|-| \mid$ & $23(92.0)$ & $2(8.0)$ & & $8(30.8)$ & $18(69.2)$ & \\
\hline$\cdot \cdot \mathrm{III}-\mathrm{IV}$ & $37(78.7)$ & $10(21.3)$ & & $24(47.1)$ & $27(52.9)$ & \\
\hline Tumour differentiation & & & 0.053 & & & 0.586 \\
\hline - Well differentiated & $15(100)$ & $0(0.0)$ & & $7(36.8)$ & $12(63.3)$ & \\
\hline - Moderately or poorly differentiated & $37(77.1)$ & $11(22.9)$ & & $23(47.9)$ & $25(52.1)$ & \\
\hline Surgery of primary tumor & & & 0.578 & & & 0.389 \\
\hline - Yes & $55(80.9)$ & $13(19.1)$ & & $32(43.8)$ & $41(56.2)$ & \\
\hline - No & $5(100.0)$ & $0(0.0)$ & & $1(20.0)$ & $4(80.0)$ & \\
\hline Surgery of metastasis & & & 0.953 & & & 0.451 \\
\hline - Yes & $13(86.7)$ & $2(13.3)$ & & $9(50.0)$ & $9(50.0)$ & \\
\hline - No & $47(81.0)$ & $11(19.0)$ & & $24(40.0)$ & $24(40.0)$ & \\
\hline Adjuvant chemotherapy & & & 0.295 & & & 0.986 \\
\hline - Yes & $28(87.5)$ & $4(12.5)$ & & $14(42.4)$ & $19(57.6)$ & \\
\hline - No & $32(78.0)$ & $9(22.0)$ & & $19(42.2)$ & $26(57.8)$ & \\
\hline Chemotherapy for advanced disease & & & 0.683 & & & 0.929 \\
\hline - Yes & $36(83.7)$ & $7(16.3)$ & & $18(41.9)$ & $25(58.1)$ & \\
\hline - No & $24(80.0)$ & $6(20.0)$ & & $15(42.9)$ & $20(57.1)$ & \\
\hline
\end{tabular}

Four SNPs were identified, three in PDGFR $\alpha$ [exon 12 (A12): c.1701A>G, rs1873778; exon 13 (A13): c.1809G >A, rs10028020; and exon 17 (A17): c.2439+58C $>\mathrm{A}$, rs2412559] and one in PDGFR $\beta$ [exon 19 (B19): c.2601A $>$ G, rs246395]. SNP B19, present in 4 CRC cell lines (LS174T, LS180, SW48, COLO205) and in 58\% of patients, had a substantial impact on overall survival, with 5-year survival rates of 51\% for patients with PDGFR B19 wild type tumors versus $17 \%$ for those harboring the SNP variant $(c .2601 \mathrm{~A}>\mathrm{G})$. This is the first study to analyze the PDGFR genotype in a series of human colorectal cancer and its correlation with different clinicopathological features, and to demonstrate a significant association of a PDGFR SNP with patients' outcome.

Angiogenesis is a complex process controlled by a number of interconnected signaling pathways, among which PDGF and their receptors play a critical role. Moreover, PDGFR has been the target for many newly developed anticancer drugs, some of them with proven efficacy in CRC (i.e. regorafenib) [7] and some that have failed to demonstrate a benefit in patients with this tumor type (i.e. sunitinib, sorafenib) $[16,17]$. Despite this, however, only few studies have analyzed the clinical implications of PDGF/PDGFR expression in colorectal 
Table 3 Overall survival according to PDGFRa and PDGFR $\beta$ mutational status

\begin{tabular}{llllll}
\hline Mutational status & $\begin{array}{l}\text { Patients } \\
\text { N (\%) }\end{array}$ & \multicolumn{5}{c}{ Overall survival } \\
\cline { 3 - 6 } & & $\begin{array}{l}\text { Median } \\
\text { (months) }\end{array}$ & \% at 5y & HR & P \\
\hline PDGFR-A13 & & & & & \\
\hline • WT (AA) & $60(82 \%)$ & 37.1 & $14 \%$ & 0.96 & 0.934 \\
\hline - SNP (AG) & $13(18 \%)$ & 21.7 & $41 \%$ & & \\
\hline PDGFR-B19 & & & & & \\
\hline • WT (AA) & $33(42 \%)$ & NR & $51 \%$ & 1.93 & 0.073 \\
\hline • SNP (AG,GG) & $45(58 \%)$ & 37.1 & $17 \%$ & & \\
\hline
\end{tabular}

WT: wild type; SNP: single nucleotide polymorphism; N: number; $5 y$ : 5 years; HR: hazard ratio; NR: not reached.

cancer. In this regard, Schimanski and cols reported that specific receptor tyrosine kinases (TK) were overexpressed in K-ras mutated CRC [22]. In particular, VEGFR1, VEGFR2 and PDGFR $\alpha$ expression, documented in $95 \%, 46 \%$ and $62 \%$ of tested samples, respectively, were significantly linked to K-ras codon 12 or 13 mutations. Whether this could translate into a higher likelihood of responding to TK inhibitors, however, is a matter of speculation. On the other hand, Wheler et al. reported, in a series of 99 human colorectal carcinomas, that co-expression of PDGFR $\alpha / \beta$, observed in $57 \%$ of tumor samples, was significantly associated with lymphatic metastasis $(\mathrm{P}=0.007)$ and advanced tumor stage $(\mathrm{P}=0.03)$ [23]. Similarly, high PDGFR $\beta$ tumor stromal expression significantly correlated with more aggressive clinical behavior in patients with breast cancer, including high histopathological grade, estrogen receptor negativity, high HER2 expression and shorter survival [24].

Nevertheless, PDGFR genetic variants had never been previously assessed in CRC patients. In our study, four genetic variants were identified, all of them corresponding to SNPs previously reported in public databases.

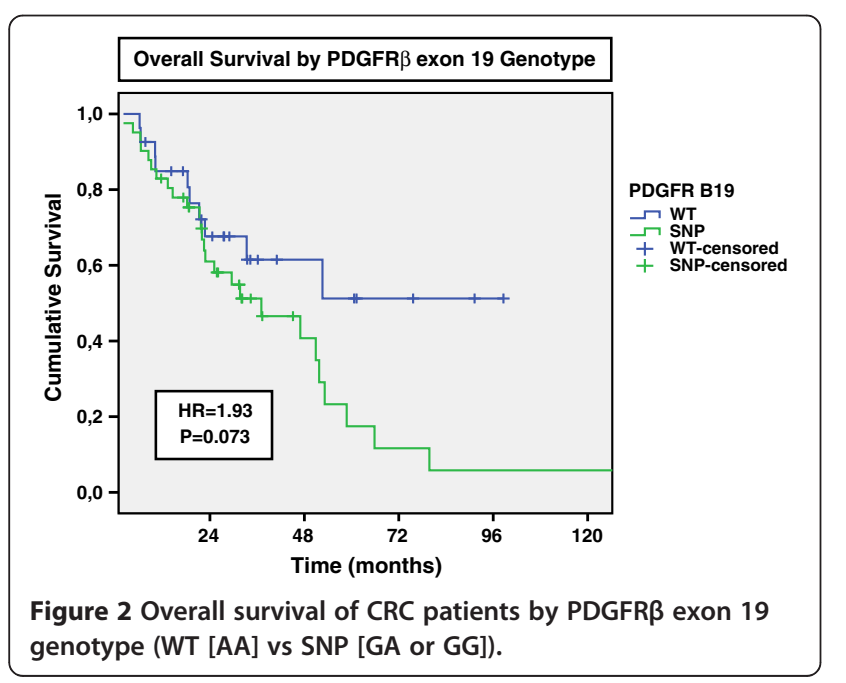

Three of them were silent mutations (A12, A13 and B19) and the other one was an intronic insertion (A17). PDGFR $\alpha$ exon 12 SNP (rs1873778), present in homozygosis in all CRC cell lines and $100 \%$ of analyzed tumor samples, has been also described in other neoplasias although in a smaller proportion of patients, including KIT and FLT3 mutation-negative core binding factor (CBFL) acute myeloid leukemias (14\% of 35 patients) [25], cervical adenosquamous carcinomas $(30 \%$ of 30 patients) [26] and gliomas (7\% of 86 patients) [27]. In this last study, no association was found between the presence of this mutation and PDGFR $\alpha$ tissue expression. Our results are in agreement with the distribution reported for a European Caucasian population at the NCBI website (http://www.ncbi.nlm.nih.gov/sites/entrez/), being the G-allele the most frequently encountered $(\mathrm{p}=0.98)$. PDGFR $\alpha$ exon 13 SNP (rs10028020), detected in heterozygosis in 2 (LS174T and LS180) of the 8 cell lines examined and in $18 \%$ of tumor samples, was associated with poorer tumor differentiation but no significant correlation was found with survival. This polymorphism had been first reported also in heterozygosis by Trojani et al. in 34\% of CBFL acute leukemias [25], although potential association of this genotype with clinical features or patient/s outcome was not explored by these authors. Finally, neither PDGFR $\alpha$ exon 17 SNP (rs2412559), identified in all of our patients, nor PDGFR $\beta$ exon 19 SNP (rs246395), present in 58\% of them, had been previously described in human cancers. PDGFR B19 SNP has been reported to be present in the general population with a frequency of $37 \%$, and was more commonly encountered in our study population among colon primary tumors (64\%) than in tumors of rectal origin (35\%). Of note, and despite not being an activating mutation, the B19 SNP was found to be a significant prognostic factor (HR: 2.89, $\mathrm{p}=0.029$ ) independent of tumor stage or patient/s age. This negative effect on patient/s survival did not differ according to primary tumor location (data not shown).

That the identified SNP in exon 19 of PDGFR $\beta$ may indeed have relevant biological implications is further supported by the fact that analysis of protein content in cell lines demonstrated the presence of the B19 SNP clearly correlated with higher protein levels of the PDGF receptor $\beta$, also in its phosphorylated state. PDGF pathway constitutive activation maintains highly active MEK, thus phosphorylating Bad and inhibiting apoptosis $[14,15]$. Increased PDGF pathway activation has been also shown to contribute to drug resistance by activating the PI3K pathway $[14,15]$. Whether or not the presence of this SNP may portend particular sensitivity to PDGFR-targeted agents is a matter of speculation but certainly deserves further investigation due to its relevant potential clinical applications. 


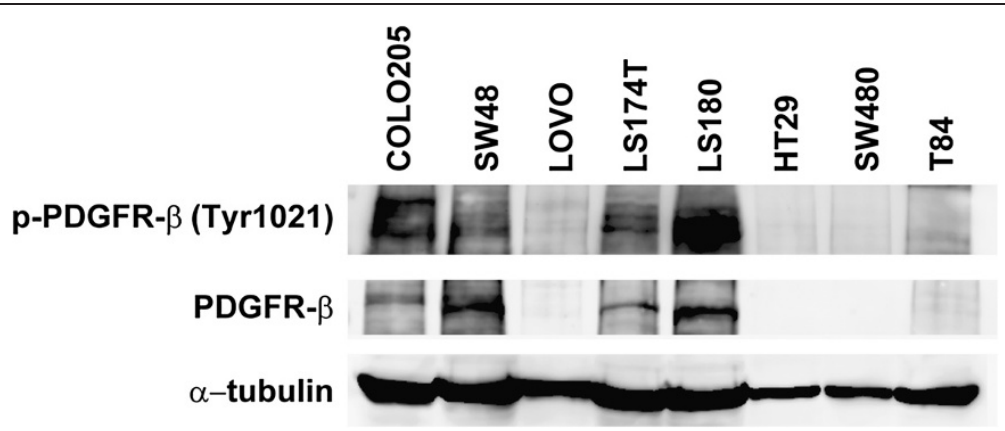

Figure 3 PDGFR $\beta$ protein expression in colon cancer cell lines. Cell lines that contained the B19 SNP in heterozygosis (LS174T, LS180, SW48 and Colo205) showed higher protein levels of PDGFR $\beta$ and $p$-PDGFRß.

On the contrary, no relevant findings were identified in our series regarding VEGFR2 TK domain SNP analysis. As in other solid tumors, overexpression of VEGF mRNA and protein has been associated with tumor progression and poor prognosis of colon carcinoma [28]. The VEGF-A gene is known to be highly polymorphic and harbors numerous SNPs, especially in the promoter, 5'- and 3'untranslated regions (UTR), which contain key regulatory elements that are sensitive to hypoxia [29]. These SNPs contribute to the high variability in VEGF production among tissues and have been associated with cancer susceptibility, progression, and anti-VEGF therapeutic response in subjects with a variety of solid tumors including colorectal cancer. For example, the $936 \mathrm{~T}$-allele has been associated with increased risk of CRC, advanced stage of disease and worse prognosis, whereas the $634 \mathrm{C}$ allele was predictive of decreased risk and improved survival. SNPs have also been identified in the VEGF receptor genes, although the literature in this topic is still very sparse. Very recently, the VEGFR-1 319 C/A SNP, located in the promoter region of the gene, has been reported to be associated with response to therapy in a cohort of 218 CRC patients treated with different bevacizumabcontaining regimens [30]. In this study by Hansen et al., response rates were significantly higher in patients homozygous for the A-allele (AA) than in patients with the C-allele genotype (CC or CA) ( $56 \%$ vs $39 \%, p=0.015)$. Similar results were also documented in bevacizumab-treated pancreatic cancer patients [31]. In addition, functional relevance has been demonstrated for several SNPs in the VEGFR-1 and VEGFR-2 genes, particularly SNPs 1192C/T (V2971I; rs2305948) and 1719T/A (H472Q; rs1870377). These SNPs are located in exons 7 and 11, and lead to amino acid changes potentially interfering with the receptor's binding affinity to VEGF-A. In the current study, however, we aimed to explore potential genetic variations in the TK domain of the VEGFR-2 (exons 17 to 26), which would be expected to have relevant functional consequences. No mutations were however detected in our study population in these gene domains.
Identification of relevant SNPs in critical genes involved in angiogenesis may therefore become valuable tools in assessing risk or predicting cancer response to therapy or prognosis. However, no consensus exists at present regarding the use of any of these for clinical decisions as many studies have reported diverging, conflicting or inconclusive results. Multiple reasons may be responsible for these discrepancies, including gender and interethnic differences in the distribution of alleles, heterogeneous study populations and small sample sizes, different sources of DNA (i.e., tumor vs germline) and different methods for SNP analyses, lack of corrections for multiple testing, links to other loci in the gene or related genes responsible for the observed effect, bias due to posttranscriptional gene regulation, or simultaneous presence of somatic or epigenetic changes that may influence outcome. Prospective validation in appropriately sized and controlled studies is therefore required before these genetic variants may be used in clinical practice.

\section{Conclusion}

In conclusion, the present study has identified, for the first time, PDGFR $\beta$ genetic variants with relevant clinical and biological implications. In particular, the G-allele genotype of PDGFR $\beta$ exon 19 SNP (rs246395), which was commonly encountered in our series of CRC patients (58\%), was associated with increased pathway activation and poorer survival. Further studies to assess the functional consequences of this genetic variant, as well as to validate its role as a prognostic marker in this disease are certainly warranted. Implications regarding its potential influence in response to PDGFR-targeted agents remain to be elucidated.

\section{Additional file}

Additional file 1: Supplementary Tables.

Competing interests

The authors declare no conflict of interest. 


\section{Authors' contributions}

Conception and design: RGC, ACM, LPA. Molecular genetic and protein analysis in human samples and cancer cell lines: ACM, Jl, SMP, MDP, SM Pathological assessment: AC, FLR. Collection and assembly of data: ACM, J, ILC, SMP, MDP, SM, PEG, RGC. Data analysis and interpretation: RGC, LPA, ACM, JI, AC, PEG. Manuscript writing: PEG, SMP, AC, LPA, RGC. Final approval of manuscript: All authors.

\section{Novelty and impact of present research}

This study has identified, for the first time, PDGFR $\beta$ genetic variants with relevant clinical and biological implications in colorectal cancer. In particular, the G-allele genotype of PDGFRß exon 19 SNP (rs246395), encountered in $58 \%$ of tumor samples from colorectal cancer patients, was associated with increased pathway activation and significantly poorer survival.

\section{Acknowledgements}

We would like to thank the technical staff from Bionostra for technical assistance. This work was supported by a grant of the Ministerio de Ciencia y Tecnologia of Spain (FIT-010000-2006-45). PEG is funded by a Rio Hortega grant (09/00207) from the Instituto de Salud Carlos III (ISCiii), Ministerio de Sanidad, Spain. SMP is funded by the ISCiii (CD1100153), Fundación Científica de la Asociacion Española Contra el Cancer (AECC), Consejeria de Salud Junta de Andalucia (PI-0224/2009) and Fundacion Mutua Madrileña (2009). MDP is funded by the ISCiii (CD0900148). LPA is funded by the ISCiii (PI081156 and PI1102688), Consejería de Innovacion, Ciencia y Empresa Junta de Andalucia (P08-CVI-04090) and the $75^{\text {th }}$ Anniversary Roche Spain Fellowship. RGC is funded by the ISCiii (PI 10.02164).

\section{Author details}

${ }^{1}$ Instituto de Biomedicina de Sevilla (IBIS) (HUVR, CSIC, Universidad de Sevilla), Sevilla, Spain. ${ }^{2}$ Medical Oncology Department, Hospital Universitario Virgen del Rocio, Sevilla, Spain. ${ }^{3}$ Pathology Department, Hospital de Fuenlabrada, Madrid, Spain. ${ }^{4}$ Bionostra Aplicaciones Biotecnológicas, S.L.U. Madrid, Spain. ${ }^{5}$ Pathology Department, Centro Integral Oncológico Clara Campal, Madrid, Spain.

Received: 22 June 2012 Accepted: 28 October 2012

Published: 12 November 2012

\section{References}

1. Ferlay J, Shin HR, Bray F, Forman D, Mathers C, Parkin DM: GLOBOCAN 2008 v1.2, Cancer Incidence and Mortality Worldwide: IARC CancerBase No. 10 [Internet]. Lyon, France: International Agency for Research on Cancer; 2010. http://globocan.iarc.fr, accessed on 31/08/2011.

2. Vieitez JM, García-Carbonero R, Aparicio J, Feliu J, González-Flores E, Grande E, Pérez-Hoyos T, Salud A, Torres E, Valero M, Valladares-Ayerbes M, Díaz-Rubio E: Recommendations and expert opinion on the adjuvant treatment of colon cáncer in Spain. Clin Trans/ Oncol 2011, 13(11):798-804.

3. García-Carbonero R, Gómez España MA, Casado Sáenz E, Alonso Orduña V, Cervantes Ruipérez A, Gallego Plazas J, García Alfonso P, Juez Martel I, González Flores E, Lomas Garrido M, Isla Casado D: SEOM clinical guidelines for the treatment of advanced colorectal cancer. Clin Transl Oncol 2010, 12(11):729-734.

4. Aranda E, Abad A, Carrato A, Cervantes A, García-Foncillas J, García Alfonso P, García Carbonero R, Gómez España A, Tabernero JM, Díaz-Rubio E: Treatment recommendations for metastatic colorectal cancer. Clin Trans/ Oncol 2011, 13(3):162-178.

5. Hurwitz H, Fehrenbacher L, Novotny W, Cartwright T, Hainsworth J, Heim W, Berlin J, Baron A, Griffing S, Holmgren E, Ferrara N, Fyfe G, Rogers B, Ross R, Kabbinavar F: Bevacizumab plus irinotecan, fluorouracil, and leucovorin for metastatic colorectal cancer. N Engl J Med 2004, 350(23):2335-2342.

6. Joulain F, Van Cutsem E, Usman I, Hoyle M, Allegra C: Aflibercept versus placebo in combination with FOLFIRI in previously treated metastatic colorectal cancer (mCRC): Mean overall survival (OS) estimation from a phase III trial (VELOUR). J Clin Oncol 2012, 30:\$3602.

7. Van Cutsem E, Sobrero AF, Siena S, Falcone A, Ychou M, Humblet $Y$, Bouche O, Mineur L, Barone C, Adenis A, Tabernero J, Yoshino T, Lenz HJ, Goldberg RM, Sargent DJ, Cihon F, Wagner A, Laurent D, Grothey A, on behalf of CORRECT Investigators: Phase III CORRECT trial of regorafenib in metastatic colorectal cancer (mCRC). J Clin Oncol 2012, 30(suppl; abstr 3502).
8. Carmeliet $P$, Jain RK: Angiogenesis in cancer and other diseases. Nature 2000, 407:249-257.

9. Weis SM, Cheresh DA: Pathophysiological consequences of VEGF-induced vascular permeability. Nature 2005, 437:497-504.

10. Sakurai T, Kudo M: Signaling pathways governing tumor angiogenesis. Oncology 2011, 81(Suppl 1):24-29.

11. Arora A, Scholar EM: Role of tyrosine kinase inhibitors in cancer therapy. J Pharmacol Exp Ther 2005, 315:971-979.

12. Ivy SP, Wick JY, Kaufman BM: An overview of small-molecule inhibitors of VEGFR signaling. Nature Rev Clin Oncol 2009, 6:569-579.

13. Hoch RV, Soriano P: Roles of PDGF in animal development. Development 2003, 130:4769-4784.

14. Yu J, Ustach C, Kim HR: Platelet-derived growth factor signaling and human cancer. J Biochem Mol Bio 2003, 36(1):49-59.

15. Andrae J, Gallini R, Betsholtz C: Role of platelet-derived growth factors in physiology and medicine. Genes Dev 2008, 22(10):1276-1312.

16. Carrato A, Swieboda-Sadlej S-S, Lim R, Roman L, Shparyk Y, Bondarenko I, Lin X, Lechuga MJ, Tursi JM, Sun Y, De la Cruz JA, Jonker D, Van Cutsem E: Final results from a randomized, double-blind, phase III study of sunitinib plus FOLFIRI vs placebo plus FOLFIRI in first-line treatment of patients (pts) with metastatic colorectal cancer. In Proceedings of the $12^{\text {th }}$ World Cancer on Gastrointestinal Cancer. Barcelona, Spain: 2010:0-0026. 30 June-3 July.

17. Tabernero J, Garcia-Carbonero R, Köhne $\mathrm{CH}$, et al: A phase $2 \mathrm{~b}$, doubleblind, randomized study evaluating the efficacy and safety of sorafenib (SOR) compared with placebo (PBO) when administered in combination with chemotherapy (modified FOLFOX6) for first-line treatment (tx) of patients (pts) with metastatic colorectal cancer (mCRC), the RESPECT trial. In Proceeding of the 2011 European Multidisciplinary Cancer Congress. Stockholm, Sweden: Abstract LBA19; 2011. 23-27 September.

18. In AJCC Cancer Staging Manual. 7th edition. Edited by Edge SB, Byrd DR, Compton CC, Fritz AG, Greene FL, Trotti A: Springer; 2010

19. Kaplan EL, Meier P: Non parametric estimation from incomplete observations. J Am Stat Soc A 1972, 35:185-206.

20. Peto R, Peto J: Asymptotically efficient rank invariant tests procedures. J R Stat Soc A 1972, 135(2):185-207.

21. Cox DR: Regression models and life tables. J R Stat SOC B 1972, 34:187-220.

22. Schimanski CC, Zimmermann T, Schmidtmann I, Gockel I, Lang H, Galle PR, Moehler M, Berger MR: K-ras mutation status correlates with the expression of VEGFR1, VEGFR2, and PDGFRalpha in colorectal cancer. Int J Colorectal Dis 2010, 25(2):181-186.

23. Wehler TC, Frerichs K, Graf C, Drescher D, Schimanski K, Biesterfeld S, Berger MR, Kanzler S, Junginger T, Galle PR, Moehler M, Gockel I, Schimanski CC: PDGFRalpha/beta expression correlates with the metastatic behavior of human colorectal cancer: a possible rationale for a molecular targeting strategy. Oncol Rep 2008, 19(3):697-704.

24. Paulsson J, Sjöblom T, Micke P, Pontén F, Landberg G, Heldin CH, Bergh J, Brennan DJ, Jirström K, Ostman A: Prognostic significance of stromal platelet-derived growth factor beta-receptor expression in human breast cancer. Am J Pathol 2009, 175(1):334-341.

25. Trojani A, Ripamonti CB, Penco S, Beghini A, Nadali G, Di Bona E, Viola A, Castagnola C, Colapietro P, Grillo G, Pezzetti L, Ravelli E, Patrosso MC, Marocchi A, Cuneo A, Ferrara F, Lazzarino M, Pizzolo G, Cairoli R, Morra E: Molecular analysis of PDGFRA and PDGFRB genes by rapid single-strand conformation polymorphism (SSCP) in patients with core-binding factor leukaemias with KIT or FLT3 mutation. Anticancer Res 2008, 28(5A):2745-2751.

26. Longatto-Filho A, Pinheiro C, Martinho O, Moreira MA, Ribeiro LF, Queiroz GS, Schmitt FC, Baltazar F, Reis RM: Molecular characterization of EGFR, PDGFRA and VEGFR2 in cervical adenosquamous carcinoma. BMC Cancer 2009, 9:212.

27. Martinho O, Longatto-Filho A, Lambros MB, Martins A, Pinheiro C, Silva A, Pardal F, Amorim J, Mackay A, Milanezi F, Tamber N, Fenwick K, Ashworth A, Reis-Filho JS, Lopes JM, Reis RM: Expression, mutation and copy number analysis of platelet-derived growth factor receptor A (PDGFRA) and its ligand PDGFA in gliomas. Br J Cancer 2009, 101(6):973-982.

28. Hansen TF, Jakobsen A: Clinical implications of genetic variations in the VEGF system in relation to colorectal cancer. Pharmacogenomics. 2011 12(12):1681-1693.

29. Jain $L$, Vargo CA, Danesi $R$, Sissung TM, Price DK, Venzon D, Venitz J, Figg WD: The role of vascular endothelial growth factor SNPs as predictive 
and prognostic markers for major solid tumors. Mol Cancer Ther 2009, 8:2496-2508.

30. Hansen TF, Christensen RD, Andersen RF, Spindler KL, Johnsson A, Jakobsen A: The predictive value of single nucleotide polymorphisms in the VEGF system to the efficacy of first-line treatment with bevacizumab plus chemotherapy in patients with metastatic colorectal cancer: Results from the Nordic ACT trial. Int J Colorectal Dis 2012, 27(6):715-720.

31. Lambrechts D, Claes B, Delmar P, Reumers J, Mazzone M, Yesilyurt BT, Devlieger R, Verslype C, Tejpar S, Wildiers H, de Haas S, Carmeliet P, Scherer SJ, Van Cutsem E: VEGF pathway genetic variants as biomarkers of treatment outcome with bevacizumab: an analysis of data from the AViTA and AVOREN randomised trials. Lancet Oncol 2012, 13(7):724-733.

doi:10.1186/1471-2407-12-514

Cite this article as: Estevez-Garcia et al:: PDGFRa/ $\beta$ and VEGFR2

polymorphisms in colorectal cancer: incidence and implications in clinical outcome. BMC Cancer 2012 12:514.

\section{Submit your next manuscript to BioMed Central and take full advantage of:}

- Convenient online submission

- Thorough peer review

- No space constraints or color figure charges

- Immediate publication on acceptance

- Inclusion in PubMed, CAS, Scopus and Google Scholar

- Research which is freely available for redistribution 